\title{
Optical Studies on KBr:Tl and KCl-Br:Tl Mixed Crystals
}

\author{
P. ESWARAN ${ }^{*}$, A. ANBAGI and S. NAGARAJAN \\ *Department of Physics, SMK Fomra Institute of Technology, \\ Kelambakkam, Thaiyur, Chennai, Tamilnadu-603 103, India. \\ Department of Physics, Pondicherry Engineering College, \\ Puducherry-605 014, India. \\ eswaran_74@rediffmail.com
}

Received 18 August 2009; Accepted 10 October 2009

\begin{abstract}
Optical absorption spectra of $\mathrm{KBr}_{\mathrm{Tl}}{ }^{+}(0.0125 \mathrm{~mol} \%)$ single crystals shows $\mathrm{A}, \mathrm{B}$ and $\mathrm{C}$ bands around 258,220 and $210 \mathrm{~nm}$ respectively. In $\mathrm{KCl}_{0.1} \mathrm{Br}_{0.9}: \mathrm{Tl}^{+}(0.0125 \mathrm{~mol} \%)$ mixed crystals exhibit slightly broadening of the A-band towards lower wavelength side. The broadening of the absorption spectra are suggested to be due to some complex $\mathrm{Tl}^{+}$centers involving $\mathrm{Br}^{-}$and $\mathrm{Cl}^{-}$ions formed in the mixed crystals. When excited at A, B and C-bands of $\mathrm{Tl}^{+}$ions, $\mathrm{PL}$ of $\mathrm{KBr}: \mathrm{Tl}^{+}$showed emission band around 320 with a prominent shoulder around $365 \mathrm{~nm}$. In $\mathrm{KCl}_{0.1} \mathrm{Br}_{0.9}$ mixed crystals the shoulder around $365 \mathrm{~nm}$ is not prominent due to the perturbing influence of $\mathrm{Cl}^{-}$ions. Addition bands in the excitation spectra are attributed to the presence of $\mathrm{Tl}^{+}$dimmers. PSL observed in X-ray irradiated crystals resembled their respective PL emissions indicating that PSL in them is due to $\mathrm{Tl}^{+}$ions.
\end{abstract}

Keywords: Optical absorption, $F$-centers, $\mathrm{KBr}-\mathrm{Cl}$ mixed crystals, A-band: $\mathrm{Tl}^{+}$ions.

\section{Introduction}

The optical properties of alkali halide crystals containing heavy metal ions with $\mathrm{S}^{2}$ configuration, so called $\mathrm{KI}: \mathrm{Tl}^{+}$- type phosphors, have very widely been studied as a typical material doped with impurities ${ }^{1}$. When one of these ions is substituted for an alkali ion, several absorption bands arise prominently at the low energy side of the intrinsic absorption edge of the host material. The bands named as A, B, C in the order of increasing energy and correspond to transitions from ${ }^{1} \mathrm{~S}_{0}$ ground state to ${ }^{3} \mathrm{P}_{1}$ excited state of the impurity ion. These structures depend strongly on the spin-orbit interaction of the excited states and Jahn-Teller effect ${ }^{2}$. On the other hand, there have been few investigations for impurities in mixed crystals of alkali halides ${ }^{3-7}$. The absorption, excitation and luminescence bands in alkali halide crystals containing small amount of thallium are usually attributed to $\mathrm{Tl}^{+}$ions that 
replaces cations of the host materials. In mixed alkali halide crystals, if the composition of the base materials is changed, changes occur in the spectra of the phosphors. These changes are associated with the appearance of new bands that differ from the component phosphors bands. There is no doubt that the new bands are due to centers formed by an activator in the mixed surroundings. It is noted that there is not a possibility that the appearance of additional A- bands is caused from the Jahn-Teller effect. It was clearly shown that the appearance of the new bands depends strongly on the composition ${ }^{8,9}$.

In recent years, X-ray storage phosphors have gained interest in the fields of medical $\mathrm{X}$-ray diagnostics, X-ray radiography etc. Important materials exhibiting such a behavior are the $\mathrm{Eu}^{2+}$ ions doped alkaline earth halides ${ }^{10-13}$ such as $\mathrm{BaFBr}: \mathrm{Eu}^{2+}$ and $\mathrm{RbBr}: \mathrm{Tl}^{+}$and $\mathrm{CsBr}: \mathrm{Eu}^{2+}$ $\mathrm{CsBr}-\mathrm{CsCl}$ and $\mathrm{Tl}^{+}$co-doped with $\mathrm{Eu}^{2+}$ mixed alkali halides ${ }^{14-17}$ proposed a new concept to explore the possibility of using mixed alkali halides as competitive image phosphors. In the present paper, Optical absorption (OA), Photoluminescence (PL) and Photoluminescence (PSL) studies of $\mathrm{Tl}^{+}$doped $\mathrm{KBr}$ and $\mathrm{KBr}_{0.9} \mathrm{Cl}_{0.1}$ mixed crystals are reported.

\section{Experimental}

$\mathrm{KBr}: \mathrm{Tl}^{+}$and $\mathrm{KCl}_{0.1} \mathrm{Br}_{0.9}: \mathrm{Tl}^{+}(0.0125 \mathrm{~mol} \%)$ mixed crystals were grown in from the melt. Prior to measurements the crystals were quenched from $500{ }^{\circ} \mathrm{C}$ to room temperature. The method of growth is briefly described in an earlier work ${ }^{5}$. Optical absorption measurements were carried out using UV-Visible Shimadzu 3101PC spectrophotometer at room temperature. The Photoluminescence (PL) and Photostimulated Luminescence (PSL) measurements were carried out using a JOBIN YVON - Spex Spectro- fluorometer.

\section{Results and Discussion}

\section{Optical absorption}

Figure 1 (a) shows the optical absorption spectrum of a single crystal of $\mathrm{KBr}^{-\mathrm{Tl}^{+}}(0.0125 \%)$ exhibits an absorption band at $258 \mathrm{~nm}$. On the shorter wavelength side of this band at least two overlapping bands around 220 and $210 \mathrm{~nm}$ are observed. Figure 1 (b) shows the optical absorption spectrum of $\mathrm{KCl}_{0.1} \mathrm{Br}_{0.9}: \mathrm{Tl}^{+}(0.0125 \mathrm{~mol} \%)$. It exhibits absorption broad bands at $256 \mathrm{~nm}$ and $210 \mathrm{~nm}$ with a shoulder around $220 \mathrm{~nm}$. As the undoped alkali halides are usually transparent in these wavelength ranges these absorption bands are attributable to the doped impurity $\mathrm{Tl}^{+}$ions.

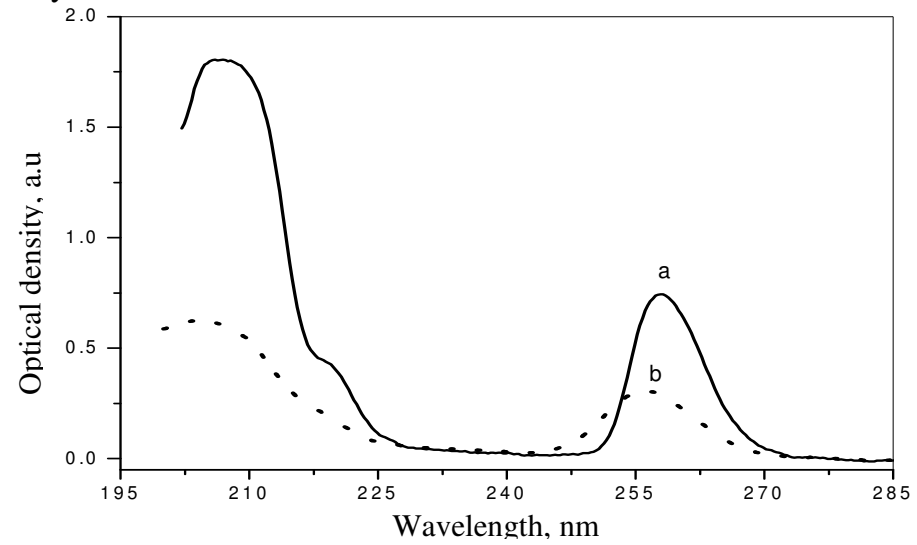

Figure 1. (a) Optical absorption spectrum of $\mathrm{KBr}_{\mathrm{Tl}}{ }^{+}(0.0125 \mathrm{~mol} \%)$, (b) Optical absorption spectrum of $\mathrm{KCl}_{0.1} \mathrm{Br}_{0.9}: \mathrm{Tl}^{+}(0.0125 \mathrm{~mol} \%)$. 
Tsuboi and Jacobs ${ }^{18}$ have observed the optical absorption bands due to $\mathrm{Tl}^{+}$ions in $\mathrm{KBr}$ at 258.2, 221.7 and $209.7 \mathrm{~nm}$. These bands were attributed to the well known A, B and C bands respectively of the $\mathrm{Tl}^{+}$ions. Comparing the optical absorption bands observed in the present study with those reported in the literature ${ }^{18}$, it is clear that these bands are due to $\mathrm{A}$, $\mathrm{B}, \mathrm{C}$ bands of the $\mathrm{Tl}^{+}$ions which have replaced substitutionally the host cations. Comparing Figures 1 (a) \& (b) one finds that $A$ - band of $\mathrm{Tl}^{+}$ions in the $\mathrm{KCl}-\mathrm{KBr}$ mixed crystals is slightly shifted to the shorter wavelength side. It may be the formation of some complex centers, though in small numbers, cannot be ruled out.

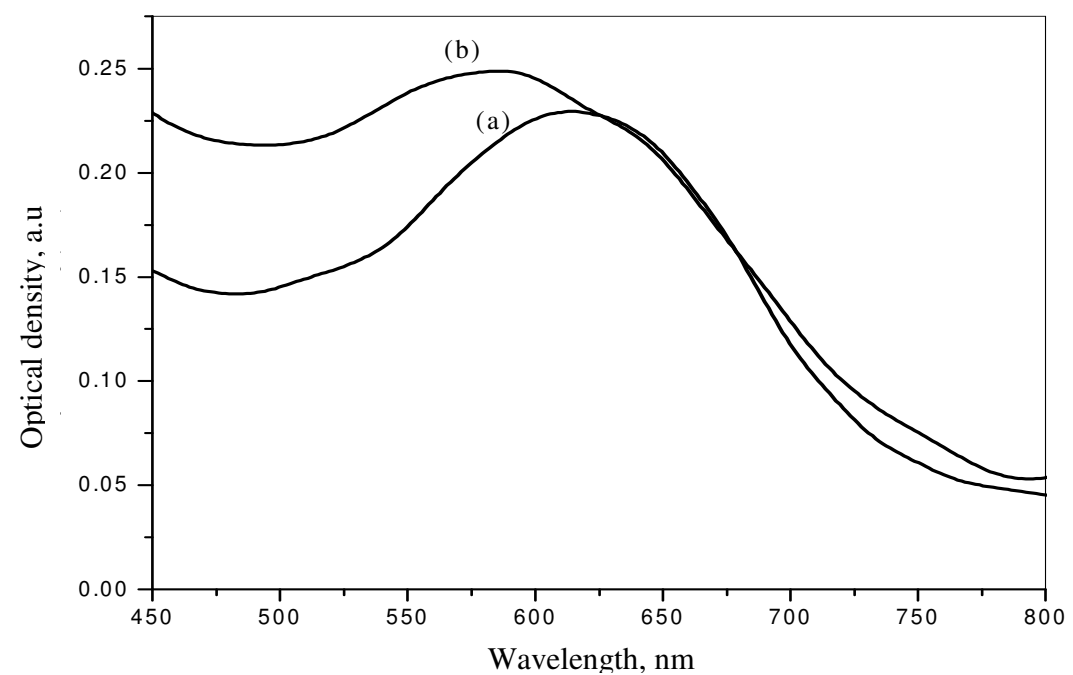

Figure 2. Normalized $F$-absorption bands (a) $\mathrm{KBr}: \mathrm{Tl}^{+}$(0.0125 mol\%), (b) $\mathrm{KCl}_{0.1} \mathrm{Br}_{0.9}: \mathrm{Tl}^{+}$ $(0.0125 \mathrm{~mol} \%)$.

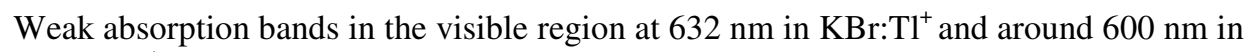
$\mathrm{KCl}_{0.1} \mathrm{Br}_{0.9}: \mathrm{Tl}^{+}$are observed after X-irradiation. These are due to $F$-centres formed in these crystals upon irradiation. Figure 2 (a) shows the $F$-absorption band observed in $\mathrm{KBr}: \mathrm{Tl}^{+}$ X-irradiated. While Figure 2 (b) shows the $F$-band of $\mathrm{KCl}_{0.1} \mathrm{Br}_{0.9}: \mathrm{Tl}^{+}(0.0125 \mathrm{~mol} \%)$ normalized to the peak value of $F$-band absorption in $\mathrm{KBr}^{-\mathrm{Tl}^{+}}$at $632 \mathrm{~nm}$. It clearly indicates that there is an additional band on the short wavelength side of $632 \mathrm{~nm}$.

It is known that $F$-centres in $\mathrm{KBr}$ absorb at $632 \mathrm{~nm}$ while $F$ - centre in $\mathrm{KCl}$ absorb ${ }^{19}$ at $564 \mathrm{~nm}$. In $\mathrm{KCl}-\mathrm{KBr}$ mixed crystal, it is likely that two types of $F$-centres are formed; one is due to the trapping of an electron by $\mathrm{Br}^{-}$vacancy while the other is due to the trapping of an electron by $\mathrm{Cl}^{-}$vacancy. Thus the broad absorption band observed around $600 \mathrm{~nm}$ may contain absorption bands due to both $F$-centres formed by capture of electron by $\mathrm{Br}^{-}$vacancy (denoted as $\mathrm{F}\left(\mathrm{Br}^{-}\right)$) and $F$-centres formed by capture of electron by $\mathrm{Cl}^{-}$vacancy (denoted as $\mathrm{F}\left(\mathrm{Cl}^{-}\right)$). Alternatively, it is suggested that the additional absorption on the short wavelength side of $632 \mathrm{~nm}$ in $\mathrm{KCl}_{0.1} \mathrm{Br}_{0.9}: \mathrm{Tl}^{+}$may be due to $\mathrm{F}\left(\mathrm{Br}^{-}\right)$centers perturbed by $\mathrm{Cl}^{-}$ions.

\section{Photoluminescence}

Photoluminescence (PL) emission spectrum of $\mathrm{KBr}_{\mathrm{Tl}}{ }^{+}$crystal excited at wavelength corresponding to the A-band maximum shows an emission band around $320 \mathrm{~nm}$ with a shoulder around $365 \mathrm{~nm}$ (Figure.3, (a)). Similar emission spectra are obtained when the 
crystal is excited at wavelengths corresponding to the $\mathrm{B}$ and $\mathrm{C}$ absorption bands but with different relative intensities. Intensity of emission for excitation at $A$-band is the highest while that for excitation at $\mathrm{C}$ band is the least.

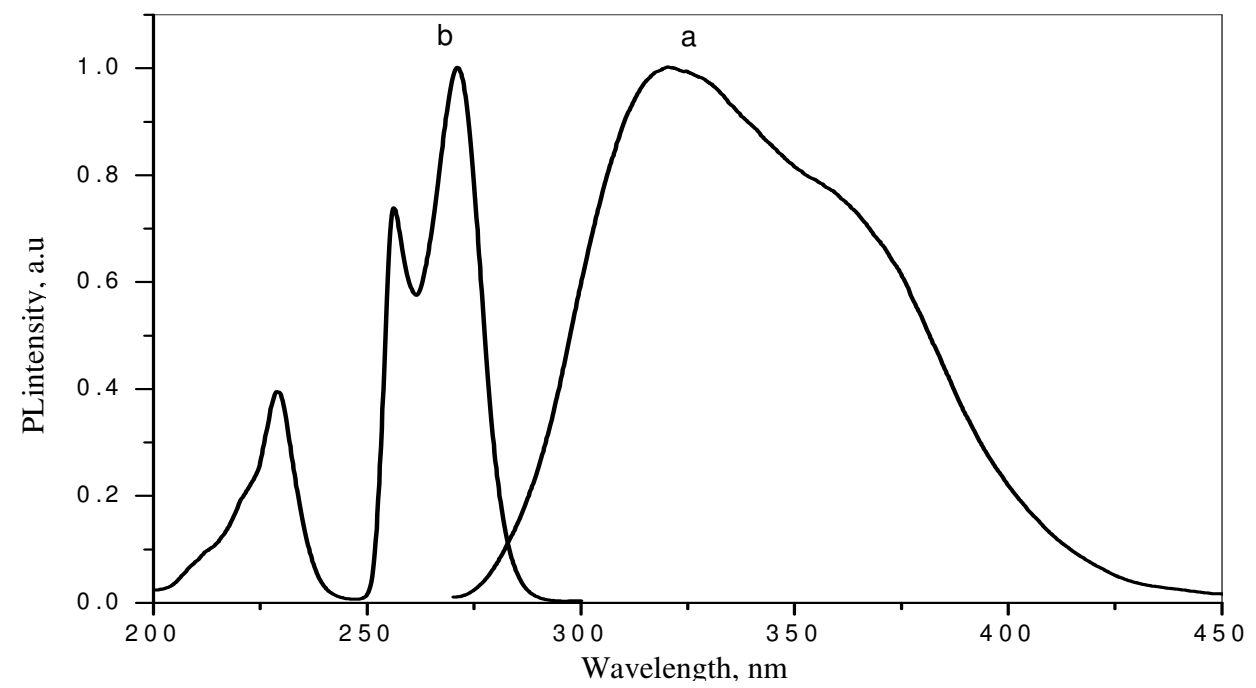

Figure 3. (a) PL emission spectrum of $\mathrm{KBr}: \mathrm{Tl}^{+}(0.0125 \mathrm{~mol} \%)$ for excitation at $A$-band $(258 \mathrm{~nm})$ and (b) PL excitation spectrum of $\mathrm{KBr} \mathrm{Tl}^{+}(0.0125 \%)$ for emission at $320 \mathrm{~nm}$.

Edgerton and Teegarden ${ }^{20}$ have observed two emission bands (designed as $\mathrm{A}_{\mathrm{T}}$ and $\mathrm{A}_{\mathrm{X}}$ emissions) in $\mathrm{KBr}_{\mathrm{Tl}}^{+}$around 310 and $363 \mathrm{~nm}$ upon excitation in any of the thallium absorption bands, $\mathrm{A}, \mathrm{B}$ and $\mathrm{C}$ at room temperature. These bands are unresolved at room temperature but are resolved at lower temperatures. Roth and Halperin ${ }^{21}$ reported two PL emission bands at 310 and $365 \mathrm{~nm}$ due to monomer $\mathrm{Tl}^{+}$ions in $\mathrm{KBr}_{\mathrm{Tl}}^{+}$at LNT. Thus the two $\mathrm{PL}$ emission bands observed in the present study are due to $\mathrm{Tl}^{+}$ions (monomer $\mathrm{Tl}^{+}$ions).

PL excitation spectra for both the emission bands at 320 and $365 \mathrm{~nm}$ show the same excitation bands at 271, 258 and $229 \mathrm{~nm}$ along with some weak shoulder around 220 and $210 \mathrm{~nm}$. Figure 3 (b) shows the PL excitation spectrum for the emission at $320 \mathrm{~nm}$.

Comparing with the absorption spectrum of $\mathrm{KBr} \mathrm{Tl}^{+}$(Figure 1 (a)), one infers that the excitation bands at 258,221 and $210 \mathrm{~nm}$ corresponds to the $\mathrm{A}, \mathrm{B}$ and $\mathrm{C}$ absorption bands respectively. However the presence of absorption bands corresponding to the 271 and $229 \mathrm{~nm}$ excitation bands is not obvious in the optical absorption spectrum of $\mathrm{KBr}_{\mathrm{Tl}}^{+}$(Figure 1 (a)). The excitation at 271 and $229 \mathrm{~nm}$ resulted in the same PL emission and no additional emission band has been observed.

Tsuboi and Jacobs ${ }^{18}$ have reported that $\mathrm{KI}$ and $\mathrm{KBr}$ crystals having more than 0.01 mole percentage of $\mathrm{Tl}^{+}$ions exhibited weak additional absorption bands (hidden under the $\mathrm{Tl}^{+}$ monomer bands) due to the formation of $\mathrm{Tl}^{+}$dimers -aggregate of pair of $\mathrm{Tl}^{+}$ions. These hidden bands have been reported to be found mainly from the excitation spectra. They also reported that, at low temperatures, excitation at the dimer bands resulted in an additional emission at $443 \mathrm{~nm}$. In the present study the additional excitation bands at 271 and $229 \mathrm{~nm}$ have their peak position very close to the reported $A_{1}$ and $B_{1}$ side bands respectively. The higher intensity of the $A_{1}$ side band suggests that a quite a good number of dimers have been formed in these crystals. However, the excitation at 271 and $229 \mathrm{~nm}$ did not result in any additional emission band. 
PL emission spectrum of $\mathrm{KCl}_{0.1} \mathrm{Br}_{0.9}: \mathrm{Tl}^{+}(0.0125 \%)$ excited at $A$-band shows an emission band at $320 \mathrm{~nm}$ in the region between $275-450 \mathrm{~nm}$ (Figure.4 (a)). Similar emission spectra are obtained when the crystal is excited at $\mathrm{B}$ and $\mathrm{C}$ bands but with different relative intensities (figure not shown). Emission band observed at $365 \mathrm{~nm}$ in $\mathrm{KBr}_{\mathrm{Tl}}{ }^{+}$(Figure 3(a)) is not prominently seen in $\mathrm{KCl}_{0.1} \mathrm{Br}_{0.9}: \mathrm{Tl}^{+}$. This may be due to the perturbing influence of the $\mathrm{Cl}^{-}$ions present in this crystal.

PL excitation spectrum for the $320 \mathrm{~nm}$ emission exhibits broad excitation bands around 259, 220 and $210 \mathrm{~nm}$ (Figure 4 (b)) which are close to the peak positions of A, B, C absorption bands of $\mathrm{KBr}: \mathrm{Tl}^{+}$. The excitation at 220 and $210 \mathrm{~nm}$ resulted in the same emission and no additional emission bands have been observed. The excitation band showed a broader A-band (half width $=0.33 \mathrm{eV}$ ) when compared to that of the $A$ - absorption band whose half width is about $0.202 \mathrm{eV}$ only. This broadening of $A$ - excitation band may be an indication that, $A$-side bands are hidden under the $A$-excitation band.

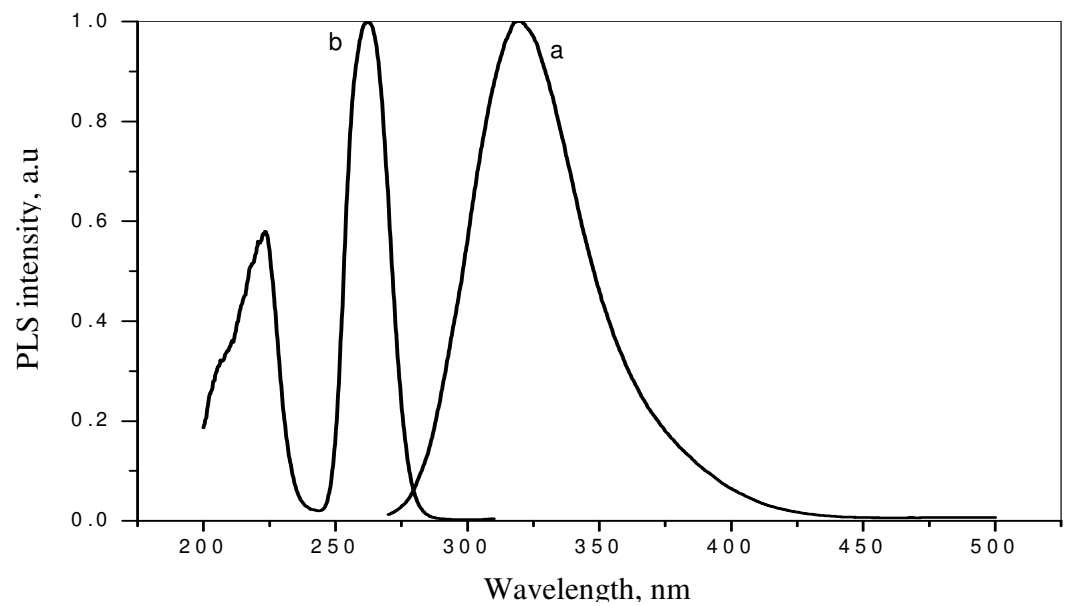

Figure 4. (a) $\mathrm{PL}$ emission spectrum of $\mathrm{KCl}_{0.1} \mathrm{Br}_{0 . .9}: \mathrm{Tl}^{+}(0.0125 \%)$ for excitation at $A$-band, (b) PL excitation spectrum of $\mathrm{KCl}_{0.1} \mathrm{Br}_{0 . .9}: \mathrm{Tl}^{+}(0.0125 \%)$ for emission at $320 \mathrm{~nm}$.

It has been reported that in $\mathrm{ns}^{2}$ ions doped mixed alkali halide crystals such as $\mathrm{Tl}^{+}$doped $\mathrm{KCl}-\mathrm{KI}$ and $\mathrm{KBr}-\mathrm{KI}$, iodine anions are collected preferentially around the impurity cations as their nearest neighbours ${ }^{8}$. The polarisability of $\mathrm{I}^{-}$is larger than that of $\mathrm{Br}^{-}$ions and also the polarization effect of $\mathrm{Tl}^{+}$ions is more pronounced than that of $\mathrm{K}^{+}$ions. Hence the preferred position of $\mathrm{I}^{-}$in the surrounding of the activator ion could be explained by the larger polarization energy of the ion pair $\mathrm{Tl}^{+}-\mathrm{I}^{-}$than that of $\mathrm{K}^{+}-\mathrm{Br}^{-}$and $\mathrm{K}^{+}-\mathrm{I}^{-}$. Similar arguments have been put forward for the formation of $\left[\mathrm{SnCl}_{6-\mathrm{x}}+\right.$ Cation Vacancy] complex centers in the $\mathrm{KCl}-\mathrm{KI}\left(\mathrm{Sn}^{2+}\right)$ mixed crystals ${ }^{22}$. In $\mathrm{Tl}^{+}$doped $\mathrm{KCl}-\mathrm{KI}$ and $\mathrm{KBr}-\mathrm{KI}$ mixed crystals, it has been suggested that complex $\mathrm{Tl}^{+}$centers of the type $\mathrm{TlX}_{6-\mathrm{n}} \mathrm{I}_{\mathrm{n}}(\mathrm{X}=\mathrm{Cl}$ or $\mathrm{Br}$ depending on the host, $\mathrm{n}=0,1,2 \ldots 6$ ) are formed ${ }^{9}$. Kleemann and Fischer have suggested that $\mathrm{TlBr}_{6}, \mathrm{TlBr}_{5} \mathrm{I}$, $\mathrm{TlBr}_{4} \mathrm{I}_{2}$ and $\mathrm{TlBr}_{3} \mathrm{I}_{3}$ complex centers (i.e., $\mathrm{TlX}_{6-\mathrm{n}} \mathrm{I}_{\mathrm{n}}$ centers with $\mathrm{n}=0,1,2,3$ ) are formed predominantly in $\mathrm{KBr}-\mathrm{KI}$ mixed crystals doped with $\mathrm{Tl}^{+}$ions. The broad A-band absorption due to these complex centers $\left(\mathrm{TlX}_{6-\mathrm{n}} \mathrm{I}_{\mathrm{n}}\right)$ with number of nearest neighbor iodine anions, $\mathrm{n}=$ $0,1,2,3$ observed. The absorption bands observed at 4.8, 4.66, 4.55 and $4.44 \mathrm{ev}$ at $20 \mathrm{~K}$ in $\mathrm{KBr}-\mathrm{KI}$ mixed crystals were designated as $\mathrm{A}_{0}, \mathrm{~A}_{1}, \mathrm{~A}_{2}$ and $\mathrm{A}_{3}$ bands respectively. The broadening of the $A$-band absorption/ excitation (as well as $\mathrm{B}$ and $\mathrm{C}$ bands) in $\mathrm{KCl}_{0.1} \mathrm{Br}_{0 . .9}: \mathrm{Tl}^{+}(0.0125 \%)$ (Present study) is also similar to that observed in $\mathrm{KBr}-\mathrm{KI}$ mixed 
crystals ${ }^{9}$. Hence the broadening of the mixed crystal of the present study is attributed to the appearance of new bands due to the complex $\mathrm{Tl}^{+}$centres in the mixed configuration with both $\mathrm{Cl}^{-}$and $\mathrm{Br}^{-}$ions as nearest neighbours to the $\mathrm{Tl}^{+}$ions. Similar effects have been observed in the case of B and C-bands of these complex $\mathrm{Tl}^{+}$centers in the mixed crystals. As the formation of aggregate centers of $\mathrm{Tl}^{+}$ions also produces a similar shift towards low energy side, the broadening may also be partially due to the formation of such $\mathrm{Tl}^{+}$ aggregates centers.

\section{Photostimulated luminescence}

Figure 5 (A). Shows the PSL emission spectrum of X- irradiated $\mathrm{KBr}: \mathrm{Tl}^{+}$crystal stimulated at F-band. $\mathrm{KBr}_{\mathrm{Tl}}^{+}$crystal shows a PSL emission band around $320 \mathrm{~nm}$ with a shoulder around $365 \mathrm{~nm}$. These emission bands are similar to the PL emission bands excited at the wavelength corresponding to the A-band maximum and hence it may be concluded that PSL emission in X-irradiated $\mathrm{KBr}: \mathrm{Tl}^{+}$crystals is due to $\mathrm{Tl}^{+}$ions.

PSL stimulation spectra for the emission at $320 \mathrm{~nm}$ showed maximum around $633 \mathrm{~nm}$, which is close to the peak wavelength of $\mathrm{F}$ - band absorption in $\mathrm{KCl}_{0.1} \mathrm{Br}_{0 . .9}: \mathrm{Tl}^{+}$shown in Figure (Figure.5. (B), curve b).

The PSL emission spectrum of X-irradiated $\mathrm{KCl}_{0.1} \mathrm{Br}_{0.9}: \mathrm{Tl}^{+}$crystal stimulated at $633 \mathrm{~nm}$ shows PSL emission around $325 \mathrm{~nm}$ with a weak shoulder around $370 \mathrm{~nm}$ crystal (Figure.5. (B), curve a). This PSL emission spectrum is more or less similar to the PL emission spectrum of $\mathrm{KCl}_{0.1} \mathrm{Br}_{0.9}: \mathrm{Tl}^{+}$. The corresponding stimulation spectrum showed a band with maximum around $630 \mathrm{~nm}$ indication that $\mathrm{F}\left(\mathrm{Br}^{-}\right)$centers play a major role in the PSL emission of $\mathrm{KCl}_{0.1} \mathrm{Br}_{0.9}: \mathrm{Tl}^{+}$crystals

Von Seggern et al. ${ }^{11}$, studied the PSL emission and stimulation spectra of $\mathrm{RbBr}: \mathrm{Tl}$ at $206 \mathrm{~K}$ and at ROOM TEMPERATURE. Stimulation spectrum was observed at $695 \mathrm{~nm}$. This wavelength agrees well with the published data for $F$-absorption band maximum of $\mathrm{RbBr}$. Due to quantitative agreement between the stimulation spectrum and the $F$-centre absorption band the nature of the electron trap was attributed to the $F$ - centres in RbBr:Tl.

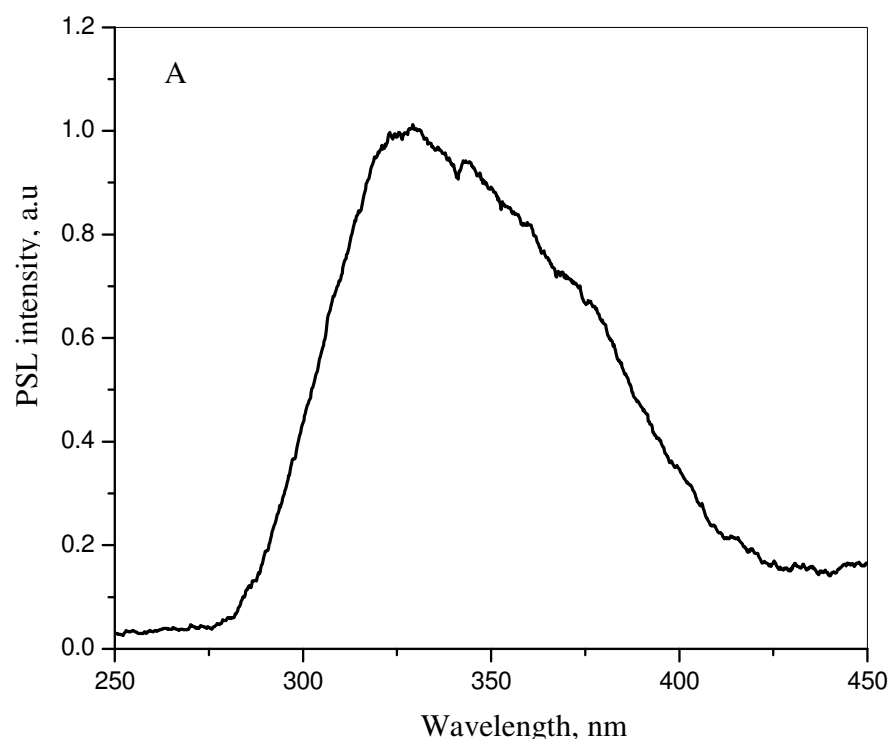




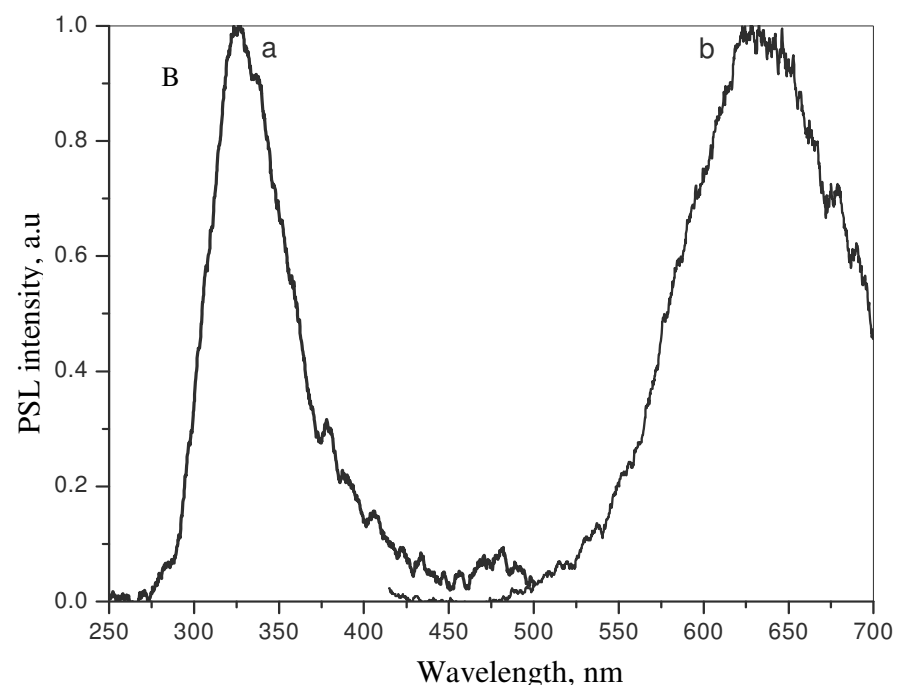

Figure 5. (A). PSL emission spectrum of $\mathrm{KBr}: \mathrm{Tl}^{+}(0.0125 \mathrm{~mol} \%)$, (Figure (B), curve a ) PSL emission spectrum of $\mathrm{KCl}_{0.1} \mathrm{Br}_{0 . .}: \mathrm{Tl}^{+}(0.0125 \%)$ for stimulation in the $F$-band and (Figure (B), curve b) PSL stimulation spectrum of $\mathrm{KCl}_{0.1} \mathrm{Br}_{0 . .9}: \mathrm{Tl}^{+}(0.0125 \%)$ for $320 \mathrm{~nm}$ emission.

From the above results it may be suggested that during $\mathrm{X}$ - irradiation, $\mathrm{Tl}^{+}$ions trap holes becoming $\mathrm{Tl}^{++}$ions while the corresponding electrons are trapped at anion vacancies forming $F$ - centres. Trapping of some holes by $\mathrm{Tl}^{+}$dimers or $\mathrm{Tl}^{+}$ion complexes may also happen $^{21}$. During PSL, stimulation at $F$-band may result in the release of $F$-centre electrons into the conduction band, which are mobile. When these mobile electrons recombine with $\mathrm{Tl}^{2+}$ ions, they are converted into $\mathrm{Tl}^{+}$ions in the excited state $\left({ }^{3} \mathrm{P}_{1}\right)$. When they relax to the ground state $\left({ }^{1} \mathrm{~S}_{0}\right)$ they emit the characteristic $\mathrm{Tl}^{+}$emission. Recombination of electrons with hole trapped $\mathrm{Tl}^{+}$aggregates may also result in monomer like emission as observed in PL.

A similar mechanism was proposed by Von Seggern et al ${ }^{l 1}$., in $\mathrm{RbBr}_{\mathrm{Tl}}{ }^{+}$. However they observed in a later study that the temperature dependence of PSL was solely determined by lifetime of $\mathrm{Tl}^{+}$ions in the range $50-500 \mathrm{~K}$ and that there was no decrease in PSL below $80 \mathrm{~K}$ where release of electrons into conduction band becomes less probable ${ }^{11}$. This observation prompted them to propose a tunneling mechanism.

\section{Conclusion}

In the present study, optical absorption spectra of $\mathrm{KBr}^{\mathrm{T}}{ }^{+}$single crystal exhibited the characteristics $\mathrm{A}, \mathrm{B}$ and $\mathrm{C}$ bands of $\mathrm{Tl}^{+}$ions. In mixed crystal slight changes in the half width of the absorption and excitation spectra doping with $\mathrm{KBr}$ due to influence of $\mathrm{Cl}^{-}$ions. It may be the formation of some complex centers, though in small numbers, cannot be ruled out. PSL emission bands observed in $\mathrm{KBr} \mathrm{Tl}^{+}$emission band very closely resemble with $\mathrm{PL}$ emission bands. PSL studies of the $\mathrm{KCl}_{0.1} \mathrm{Br}_{0.9}: \mathrm{Tl}^{+}$mixed crystal suggested that $\mathrm{F}$ and $\mathrm{Tl}^{2+}$ centers play the role of electron trapped centers and the hole trapped centers, respectively, in the PSL process.

\section{References}

1. Fowler W B, Physics of Color Centers, Academic Press, New York, 1968, Chapter 2, 53-179.

2. Toyozawa Y and Inoue M, J Phys Soc Jpn., 1995, 19, 1663. 
3. Tarasov L I and Shatseva L S, Opt Spectrosc., 1976, 41, 605.

4. Cruz Z E, Negron A, A. Ramos A, Ramos B S, Hernandez A J, Jaque F and Murrieta S H, Radiat Phys Chem., 2001, 61, 443.

5. Nagarajan S and Eswaran P, Nucl Inst Meth Res B., 2009, 267, 1800.

6. Eswaran P, Ravisankar R and Nagarajan S, Nucl Sci Tech., 2009, 20, 208.

7. Inaba M and Hashimoto S, Phys Stat Sol (b), 1996, 195, 433.

8. Hashimoto S, Mori M, Ichimura N, Kondo H and Yoshiyuki Harada, Thin Solid Film., 2001, 386, 14.

9. Kleemann W and Fischer F, Z Physik., 1966, 197, 75.

10. Takahashi K, Khoda K, Miyahara J, Kamemitsu Y, Amitani K and Shionoyo S, J Lumin., 1984, 31-32, 266.

11. Von Seggern H, Meijerink A, Voigt A and Winnacker T, Appl Phys., 1989, 66, 4418.

12. Weidner M, Batentschuk M, Meister F, Osvet A, Winnacker A, Tahon J P and Leblans P, Radiat Measur., 2007, 42, 661.

13. Ganapathi Subramani N, Selvasekarapandian S and Pal H, Mater Lett., 2003, 57, 2021.

14. Nagarajan S and Suderkodi R, J Alloys Compd., 2009, 468, 558.

15. Nagarajan S and Suderkodi R, Luminescence, 2009, 24, 162.

16. Nagarajan S and Suderkodi R, Radiation Effects and Defects in Solids 2008, 163, 915.

17. Nagarajan S and Suderkodi R, Nucl Inst Meth Res B., 2008, 266, 3595.

18. Taiju Tsuboi and Jacobs P W M., J Phys Chem Solids, 1991, 52, 69.

19. Cruz Z E, Barboza-Flores M, Chernov V, Melendrez R, Gestelum S, Ramos B S, Hernandez A J and Murrieta S H, Phys Stat Sol (c)., 2005, 2, 568.

20. Edgerton K and Teegarden, Phys Rev., 1996, 136A, 1091.

21. Roth M and Halperin A., J Lumin., 1979, 20, 227.

22. Kynev S K and Tabakova, J Phys C: Solid Stat Phys., 1971, 4, 1069. 


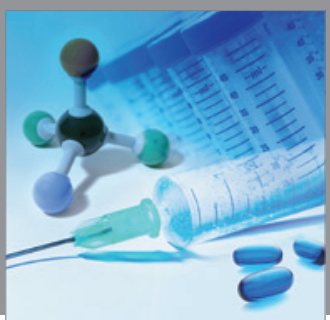

International Journal of

Medicinal Chemistry

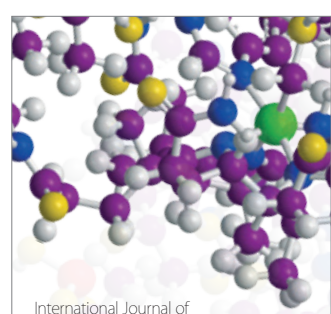

Carbohydrate Chemistry

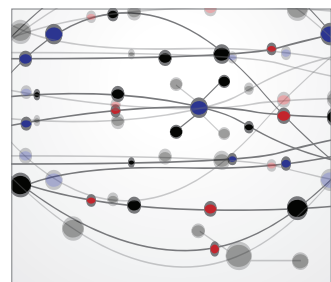

The Scientific World Journal
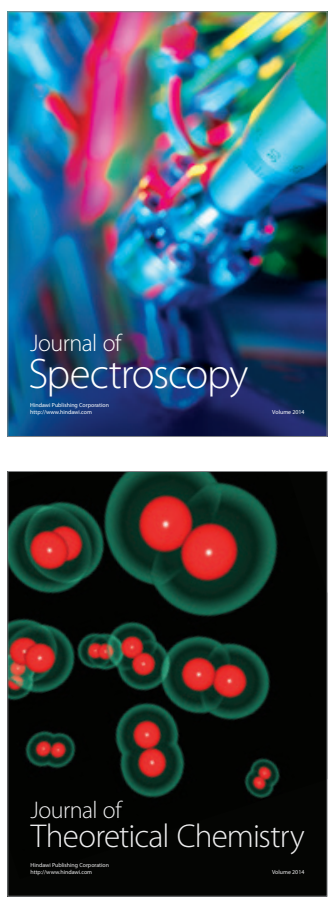
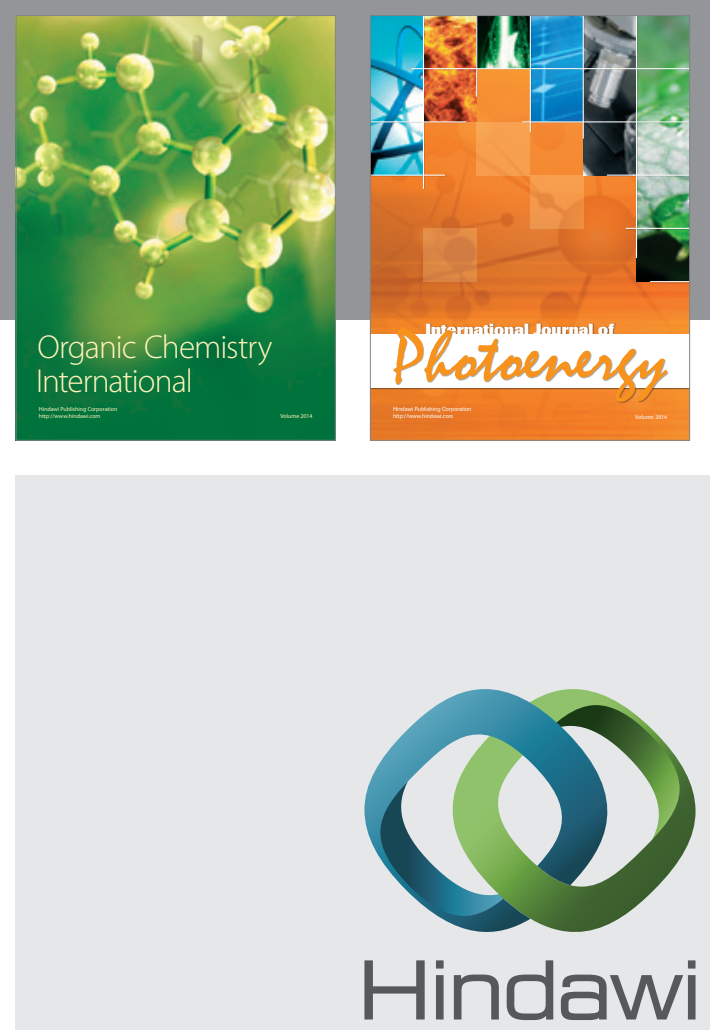

Submit your manuscripts at

http://www.hindawi.com
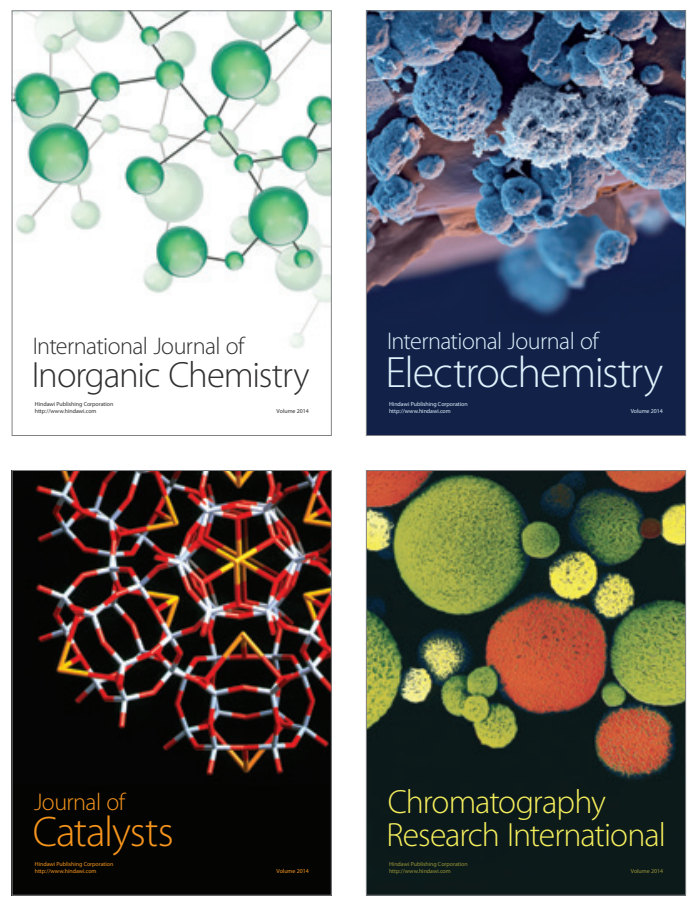
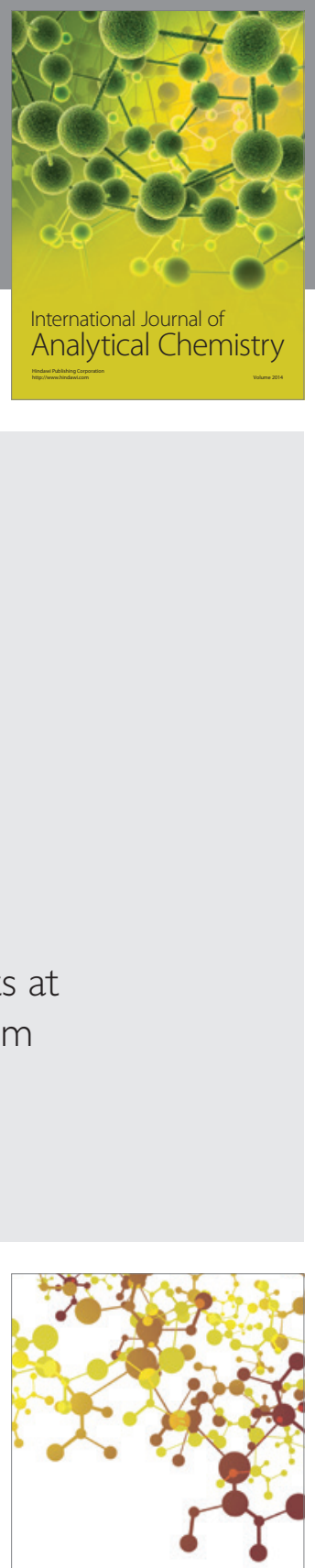

Journal of

Applied Chemistry
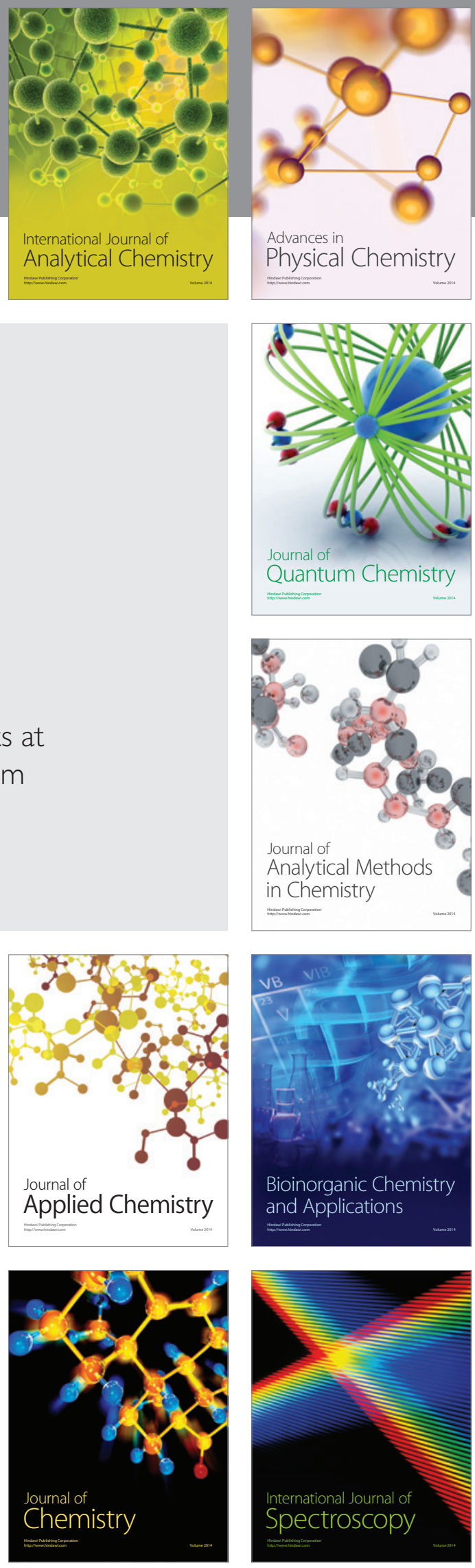